\title{
Persistence and Dose Escalation of Tumor Necrosis Factor Inhibitors in US Veterans with Rheumatoid Arthritis
}

\author{
Grant W. Cannon, Scott L. DuVall, Candace L. Haroldsen, Liron Caplan, Jeffrey R. Curtis, \\ Kaleb Michaud, Ted R. Mikuls, Andreas Reimold, David H. Collier, David J. Harrison, \\ George J. Joseph, and Brian C. Sauer
}

\begin{abstract}
Objective. Limited evidence exists comparing the persistence, effectiveness, and costs of biologic therapies for rheumatoid arthritis in clinical practice. Comparative effectiveness studies are needed to understand real-world experience with these agents. We evaluated treatment patterns, costs, and effectiveness of tumor necrosis factor inhibitor (TNFi) agents in patients enrolled in the Veterans Affairs Rheumatoid Arthritis (VARA) registry.

Methods. Observational data from the VARA registry and linked administrative databases were analyzed. Longitudinal data from VARA patients initiating adalimumab (ADA), etanercept (ETN), or infliximab (IFX) from 2003 (the date all agents were available within the Veteran Affairs) to 2010 were analyzed. Outcomes included Disease Activity Score using 28 joints (DAS28), treatment persistence, dose escalation, and direct costs of drugs and drug administration.

Results. For 563 eligible patients, baseline DAS28, DAS28 improvements, and persistence on initial treatment were similar across agents. Fewer patients receiving ETN $(n=5 / 290 ; 2 \%)$ underwent dose escalation than did patients taking ADA $(n=32 / 204 ; 16 \%)$ or IFX $(n=44 / 69 ; 64 \%)$. Annual costs for first course of TNFi therapy were lower for injectable ADA $(\$ 13,100$ US) and ETN $(\$ 13,500$ US) than for intravenously administered IFX (\$16,900 US).

Conclusion. Despite similar persistence and clinical disease activity for these TNFi agents, rates of dose escalation were highest with ADA and IFX. Higher overall costs were noted for IFX without increases in effectiveness. (First Release Aug 15 2014; J Rheumatol 2014;41:1935-43; doi:10.3899/ jrheum.140164)
\end{abstract}

Key Indexing Terms:

RHEUMATOID ARTHRITIS ADALIMUMAB ETANERCEPT INFLIXIMAB

Rheumatoid arthritis (RA) is a serious disease with significant morbidity and mortality ${ }^{1,2}$. Effective therapies for RA can significantly modify RA progression. Conventional disease-modifying antirheumatic drugs $3,4,5$, tumor necrosis factor inhibitor (TNFi) agents $6,7,8,9$, and other biologic $\operatorname{drugs}_{\mathrm{s}} 10,11,12,13,14,15$ have demonstrated effectiveness at improving the signs and symptoms of RA and reducing the development and progression of erosive disease $6,7,8,16,17$. TNFi agents are the most commonly used biologic agents for the treatment of RA.

Unfortunately, TNFi agents are not universally effective. When TNFi agents are less effective than desired, clinicians
From the Veterans Affairs Salt Lake City Health Care System; University of Utah School of Medicine, Salt Lake City, Utah; Denver Veterans Affairs (VA); University of Colorado, Denver, Colorado; University of Alabama at Birmingham, Birmingham, Alabama; the University of Nebraska Medical Center; Omaha VA, Omaha, Nebraska; the National Data Bank for Rheumatic Diseases, Wichita, Kansas; Dallas VA; University of Texas Southwestern, Dallas, Texas; Amgen Inc., Thousand Oaks, California, USA.

Sponsored by Immunex, a wholly owned subsidiary of Amgen Inc., and by Wyeth, which was acquired by Pfizer in October 2009, and by VA Health Services Research and Development Grant SHP 08-172.

G.W. Cannon, MD, Associate Chief of Staff of Academic Affiliations; S.L. DuVall, PhD, Associate Director, VA Informatics and Computing Infrastructure and Research Assistant Professor; C.L. Haroldsen, MSPH, Senior Programmer/Analyst; B.C. Sauer, PhD, MS, Associate Professor, Veterans Affairs Salt Lake City Health Care System, University of Utah School of Medicine; L. Caplan, MD, PhD, Associate Professor of Medicine/Rheumatology, Denver VA, University of Colorado; J.R. Curtis, MD, MS, MPH, William J. Koopman Endowed Professor in Rheumatology and Immunology, Director, University of Alabama Birmingham (UAB) Arthritis Clinical Intervention Program, Co-director, UAB Center for Education and Research on Therapeutics, Co-director, UAB PharmacoEpidemiology and Economic Research Group, University of Alabama at Birmingham; K. Michaud, PhD, Assistant Professor of Medicine, Co-director, University of Nebraska Medical Center, National Data Bank for Rheumatic Diseases; T.R. Mikuls, MD, Staff Physician and Researcher, Professor of Internal Medicine and Rheumatology, Omaha VA, University of Nebraska Medical Center; A. Reimold, MD, Chief, Rheumatology Section, Associate Professor of Medicine, Dallas VA, University of Texas Southwestern; D.H. Collier, MD, Clinical Research Medical Director; D.J. Harrison, PhD, Health Economics Director, Amgen Inc.; G.J. Joseph, PhD, Health Economics Senior Manager, former employee of Amgen Inc

Address correspondence to Dr. G.W. Cannon, Dr. George E. Wahlen VA Medical Center, 500 Foothill Drive, Salt Lake City, Utah 84148, USA. E-mail:Grant.Cannon@va.gov

Full Release Article. For details see Reprints/Permissions at jrheum.org Accepted for publication June 16, 2014.

Personal non-commercial use only. The Journal of Rheumatology Copyright @ $\subset$ 2014. All rights reserved 
will often switch to another TNFi or escalate the dose of the treatment ${ }^{17,18,19}$. While data from randomized clinical trials have provided some information on different doses of TNFi agents, only a few studies have evaluated the effect of dose escalation on clinical outcomes ${ }^{6,20,21}$. There is also significant cost associated with TNFi therapy, and the cost effectiveness of these agents has been challenging to evaluate $22,23,24,25,26$. There is a critical need for information on the use of TNFi agents in clinical practice over longterm observation periods to fully understand these issues.

The US Veterans Affairs Rheumatoid Arthritis (VARA) registry is a prospective, multicentered, observational study collecting clinical information during routine clinical practice that can be correlated with VA pharmacy databases. Merging data from the VARA registry with these VA administrative databases has been a successful strategy to evaluate the effectiveness of arthritis medications ${ }^{27}$, including the effect of methotrexate (MTX) adherence on clinical outcomes in $\mathrm{RA}^{28}$. Similar methods can now be used to evaluate persistence and dose escalation with TNFi agents.

The primary objective of our study was to identify the initial VA-based course of TNFi therapy with the 3 most commonly used TNFi agents in the VA [adalimumab (ADA), etanercept (ETN), and infliximab (IFX)], and to determine the persistence with the first course of therapy and rates of switching to a second TNFi agent. Secondary objectives were to determine the frequency of dose escalation during the first course of TNFi therapy, evaluate the comparative effectiveness of these agents used at standard and escalated doses, and compare drug and medication-related administration costs associated with these treatments.

\section{MATERIALS AND METHODS}

Patients. The VARA registry is a prospective, multicenter, observational study involving 12 VA medical centers (Birmingham, Alabama; Brooklyn, New York; Dallas, Texas; Denver, Colorado; Jackson, Mississippi; Iowa City, Iowa; Little Rock, Arkansas; Omaha, Nebraska; Portland, Oregon; Philadelphia, Pennsylvania; Salt Lake City, Utah; and Washington, DC). The VARA registry has been fully described elsewhere ${ }^{5,29}$.

All patients who were enrolled in the VARA registry prior to September 30, 2011, were evaluated. All patients had a diagnosis of RA confirmed by a rheumatologist using the 1987 American Rheumatism Association diagnostic criteria for $\mathrm{RA}^{30}$. Patients were included in the analysis if their first TNFi therapy was initiated after March 17, 2003 (the date when all 3 TNFi agents analyzed were available for prescription within the VA) and on or prior to September 30, 2010, to allow the potential for at least 1 year of observation through September 30, 2011. Patients with any TNFi exposure prior to March 17, 2003, were excluded from our study. Patients had not received any non-TNFi biologic agents within the VA prior to their first TNFi exposure. Data were not available to evaluate biologic agent exposure prior to VA enrollment. Patients were required to have been enrolled in the VA for at least 6 months prior to their first TNFi prescription to identify patients newly initiating TNFi treatment within the VA. VA enrollment was defined as the date of the first VA-based encounter for any episode of VA-based clinical care. The selection of patients from the VARA database for inclusion in our study is shown in Figure 1.

Data sources. Three administrative VA databases were used in the analysis $^{31}$ : the Corporate Data Warehouse $(\mathrm{CDW})^{32}$, the Decision Support System (DSS) National Pharmacy Extract ${ }^{33}$, and the Pharmacy Benefits Management (PBM) database ${ }^{34}$. In these 3 datasets, information is provided on individual dispensing episodes by VA pharmacies, including the date of dispensing, number of items dispensed, expected duration of the treatment prescribed, and the prescription instructions ${ }^{34}$. In addition to these databases, chart annotation information was obtained from the VA electronic medical records. The VA stores patient medical records in electronic format in a clinical information system known as the Veterans Health Information Systems and Technology Architecture (VistA). Care providers can review and update patient medical records and place orders for medications, procedures, and tests through graphical user interfaces such as the Computerized Patient Record System or VistA Web.

Algorithms were used for ADA and ETN to integrate the information from these 3 sources (CDW, DSS, and PBM), and to define each dispensing episode for each patient. For each episode, the amount of the drug dispensed (number of syringes), patient instructions, and expected duration of the treatment episode were determined. Data for IFX infusions were not consistently detected across the 3 datasets. For all patients with an IFX infusion noted in any of the 3 databases, a full individual patient medical record review was completed by trained chart abstractors. A note in the patient's medical record was required to report an IFX infusion; if an infusion was noted in the patient's medical record, but no dose was recorded, an algorithm was used to determine the IFX dose based on the PBM and CDW databases and the infusion history. The algorithm assigned the dose based on doses recorded for infusions administered prior to and following the infusion with the missing dose.

Study outcomes. Each prescription of a TNFi agent was defined as a dispensing episode. The selection of TNFi agent was by patient and provider preference without specific prescribing guidelines. The expected days of supply were determined based on the dosing instruction and number of syringes dispensed. A drug course was defined as a period of continuous TNFi treatment consisting of 1 or more dispensing episodes without a gap of $\geq 90$ days between the expected end of the days of supply for that episode and the start of the subsequent dispensing episode. The reason for drug discontinuation was not identified. Duration of treatment was calculated as the time from the date of first treatment until the date of the expected end of the last dispensing episode for the injectable TNFi agent or 8 weeks after the last IFX infusion (based on the longest recommended dosing interval in the prescribing information). Persistence was defined as the number of days from the course start date to course end date or the date of a switch to an alternative TNFi, whichever came first.

Dose escalation was defined as a $\geq 25 \%$ increase in the average daily dose for the injectable TNFi agents ADA and ETN during a single dispensing episode in comparison with the previous dose. The daily dose was calculated by dividing the total amount of drug dispensed (mg) by the time period (days) for the prescription as noted in the dosing instruction for each dispensing episode. For IFX, dose escalation was defined as either an increase of $\geq 25 \%$ in the infusion dose without a change in dosing interval or a decrease in interval between infusions of $\geq 25 \%$ without a concurrent change in dose in comparing sequential dosing episodes.

Drug costs and associated drug administration costs were calculated based on VA pricing using the VA PBM prices. ADA has a Blanket Purchase Agreement price, while ETN and IFX have a Big 4 price (available only to the VA, Department of Defense, Public Health Service/Indian Health Service, and US Coast Guard) ${ }^{31}$. For this analysis, the most current pricing was used, specifically the January 1, 2013, to February 28, 2014, Federal Supply Schedule pricing for ADA; September 30, 2012, to September 29, 2017, pricing for ETN; and January 1, 2013, to February 29, 2016, pricing for IFX. These costs for ETN were \$139.54 US for $25 \mathrm{mg}$ syringes and $\$ 279.08$ for $50 \mathrm{mg}$ syringes; for ADA $\$ 506.78$ for $40 \mathrm{mg}$ syringes; and for IFX $\$ 456.81$ per $100 \mathrm{mg}$ vial. All IFX infusion costs were based on the cost for $100 \mathrm{mg}$ vials, rounded up to the number of $100 \mathrm{mg}$ vials used. Administration costs were based on VA dispensing costs for the injectable medications ETN and ADA, and infusion costs for IFX

Personal non-commercial use only. The Journal of Rheumatology Copyright (C) 2014. All rights reserved. 


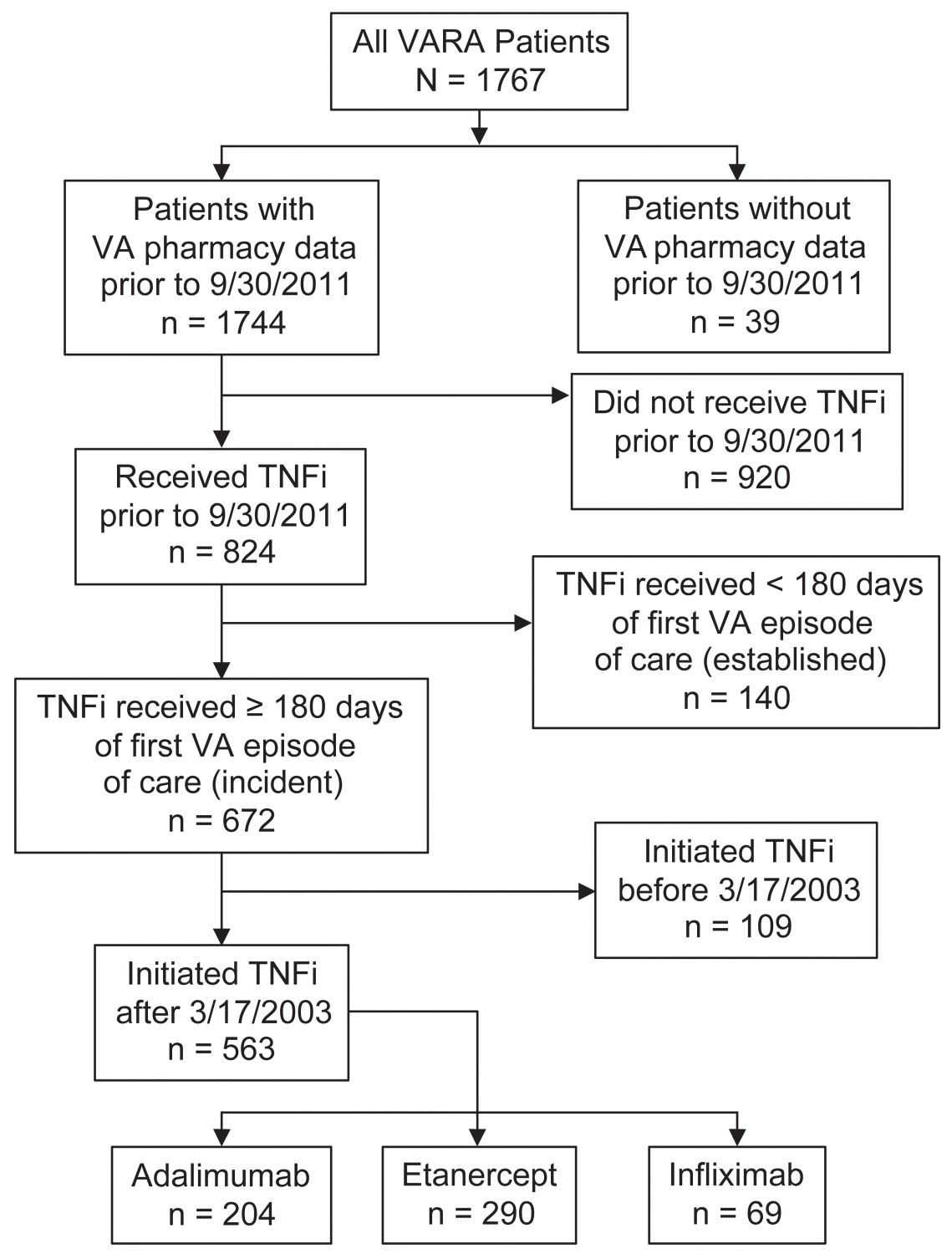

Figure 1. Patient selection. VARA: Veterans Affairs Rheumatoid Arthritis registry; TNFi: tumor necrosis factor inhibitor.

The administrative cost for each dispensing episode of ETN and ADA was $\$ 25$, and for each IV administration episode of IFX was $\$ 169.09$. The total drug costs were the sum of the direct drug costs and the drug administration costs. Costs are reported as the cost per year of treatment.

Costs were calculated for the first course of TNFi treatment for each of the 3 agents under study. The subsequent cost was then evaluated according to the initial drug assignment and calculated on an annualized basis. The second-course costs were attributed according to their initial TNFi assignment for the agent that was selected for the second course of therapy. The cost for all courses of TNFi therapy was calculated as the costs for all TNFi therapy according to the initial TNFi assignment. These total costs were designed to examine cost outcomes based on total cost for a patient according to the initial TNFi selected. For patients with dose escalation, the total medication cost included the costs of increased dosing.

Disease activity was assessed using the Disease Activity Score based on 28 joints (DAS28) ${ }^{35}$ with the erythrocyte sedimentation rate as the indicator of inflammation. The DAS28 prior to TNFi therapy was defined as the average of all reported DAS28 values from VARA enrollment until 30 days after TNFi start date. The post-TNFi DAS28 was the average of all DAS28 values beginning 90 days after TNFi course start date to allow for the medication to take effect, until the course end date. Changes in disease activity were reported as the difference between the mean DAS28 before TNFi therapy and the mean DAS28 after TNFi therapy for all patients with values at both timepoints.

Statistical analysis. Continuous data are presented as means and 95\% CI for the 3 treatment groups. Dichotomous data are presented as proportions and $95 \% \mathrm{CI}$. The focus on CI instead of $\mathrm{p}$ values provides evidence for the stability of estimates along with statistical significance testing - when the CI do not overlap between 2 groups, then the $\mathrm{p}$ values are $>0.5$ and considered significantly different ${ }^{36,37}$. Time-to-event (discontinuation and dose escalation) plots were conducted using Kaplan-Meier methodology and rates were compared using Cox proportional hazard ratios.

Scientific and ethics review. Our study was conducted in accordance with the Helsinki Declaration. All patients provided written consent upon

Personal non-commercial use only. The Journal of Rheumatology Copyright @ 2014 . All rights reserved. 
enrollment in the VARA registry. Our study was approved by the University of Utah Institutional Review Board and the VA Research Service. Our study was also approved by the Scientific and Ethical Advisory Board of the VARA registry for analysis of VARA and VA administrative data. Data were collected and evaluated by the investigators at the Salt Lake City VA Medical Center, who are responsible for the manuscript and results reported.

\section{RESULTS}

Patients. Overall, demographic characteristics at baseline were similar between patients receiving ADA, ETN, and IFX (Table 1); however, patients receiving IFX were older at the start of TNFi therapy. Most patients received combination therapy for their RA. Patients taking IFX also had a longer mean duration of disease (12.4 yrs) than did patients taking ADA (9.7 yrs) or ETN (10.5 yrs). More patients receiving IFX (70\%) were taking prednisone at baseline than were patients receiving ADA (57\%) or ETN (58\%). The median IFX infusion dose was $400 \mathrm{mg}$ (range 160-1300 mg) and the mean (SD) was 395 (133) mg.

Duration of treatment and clinical outcomes with first course of TNFi. Duration of treatment and persistence on drug with the first course of TNFi agent were similar between treatment groups (range, 24.2 to 27.9 mos; Table
2). Persistence on the first course of TNFi therapy was also similar between treatment groups (Figure 2). DAS28 at baseline was similar across treatment groups (range, 4.62 to 4.95), and no statistically significant differences in improvements in mean DAS28 score were observed between groups (Table 2). For the second course of TNFi therapy, duration of treatment was numerically longest for patients initially receiving IFX, but the differences between treatment groups were not statistically significant (Table 3 ).

Dose escalation. Fewer patients receiving ETN (2\%) underwent dose escalation during the first year on their first course than did patients receiving ADA (16\%) or IFX (64\%; Table 2). Persistence on the initial dose without escalation was longer for ETN and ADA compared with IFX ( $p<$ 0.001 ; Figure 2). All patients receiving IFX underwent dose escalation by 30 months on the first course of therapy on the drug (Figure 3).

Costs of treatment. During the first course, the costs for drug acquisition were numerically higher for IFX than ADA or ETN; however, those differences were not statistically significant (Table 3). The total annual cost of therapy, including drug costs and medication administration expenses, was statistically significantly higher for IFX than

Table 1. Baseline demographic and clinical characteristics of patients with RA receiving TNFi agents. Data are $\mathrm{n}(\%)[95 \% \mathrm{CI}]$ unless otherwise indicated.

\begin{tabular}{lccc}
\hline Characteristics & Adalimumab, $\mathrm{n}=204$ & Etanercept, $\mathrm{n}=290$ & Infliximab, $\mathrm{n}=69$ \\
\hline Age, mean yrs $(95 \% \mathrm{CI})$ & $60.3(58.8,61.8)$ & $59.8(58.6,61.1)$ & $64.8(62.5,67.1)$ \\
Sex, men & $185(91)[87,95]$ & $261(90)[87,93]$ & $62(90)[83,97]$ \\
Race & & & \\
$\quad$ White & $146(72)[65,78]$ & $227(78)[74,83]$ & $51(74)[64,84]$ \\
$\quad$ African American & $43(21)[15,27]$ & $41(14)[10,18]$ & $16(23)[13,33]$ \\
$\quad$ Hispanic & $7(3)[1,6]$ & $13(4)[2,7]$ & $2(3)[0,7]$ \\
$\quad$ American Indian/Pacific Islander & $4(2)[0,0.4]$ & $4(1)[0,3]$ & $0(0)[0,0]$ \\
$\quad$ Asian & $0(0)[0,0]$ & $1(<1)[0,1]$ & $0(0)[0,0]$ \\
$\quad$ Other/unknown & $4(2)[0,4]$ & $4(1)[0,3]$ & $0(0)[0,0]$ \\
Tobacco use & & & \\
$\quad$ Current & $63(31)[25,37]$ & $102(35)[3,41]$ & $16(23)[13,33]$ \\
$\quad$ Former & $104(51)[44,58]$ & $126(43)[38,49]$ & $39(57)[45,68]$ \\
$\quad$ Never & $37(18)[13,23]$ & $62(21)[17,26]$ & $14(20)[11,30]$ \\
RF-positive & $160(78)[73,83]$ & $231(80)[75,84]$ & $57(83)[72,90]$ \\
RA disease duration, mean yrs & $9.7(8.4,11.1)$ & $10.5(9.3,11.7)$ & $12.4(9.9,14.8)$ \\
$\quad$ 95\% CI) & $28(14)[9,18]$ & $50(17)[13,22]$ & $2(3)[0,7]$ \\
DMARD use during TNFi therapy & $176(86)[82,91]$ & $240(83)[78,87]$ & $67(97)[93,100]$ \\
$\quad$ None & $118(58)[51,65]$ & $181(62)[57,68]$ & $47(68)[57,79]$ \\
Any & $81(40)[33,46]$ & $92(32)[26,37]$ & $29(42)[30,54]$ \\
Methotrexate & $37(18)[13,23]$ & $53(18)[14,23]$ & $13(19)[10,28]$ \\
Hydroxychloroquine & $35(17)[12,22]$ & $42(14)[10,19]$ & $16(23)[13,33]$ \\
Sulfasalazine & $11(5)[2,8]$ & $6(2)[0,4]$ & $4(6)[0,11]$ \\
Leflunomide & $2(1)[0,2]$ & $8(3)[1,5]$ & $1(<1)[0,4]$ \\
Azathioprine & $1(<1)[0,1]$ & $1(<1)[0,1]$ & $0(0)[0,0]$ \\
Minocycline & $117(57)[51,64]$ & $168(58)[52,64]$ & $48(70)[59,80]$ \\
Auranofin & & & \\
Prednisone use & & & \\
\hline
\end{tabular}

RA: rheumatoid arthritis; TNFi: tumor necrosis factor inhibitor; RF: rheumatoid factor; DMARD: disease-modifying antirheumatic drug. 
Table 2. Duration and clinical outcomes with the first course of TNFi in patients with RA.

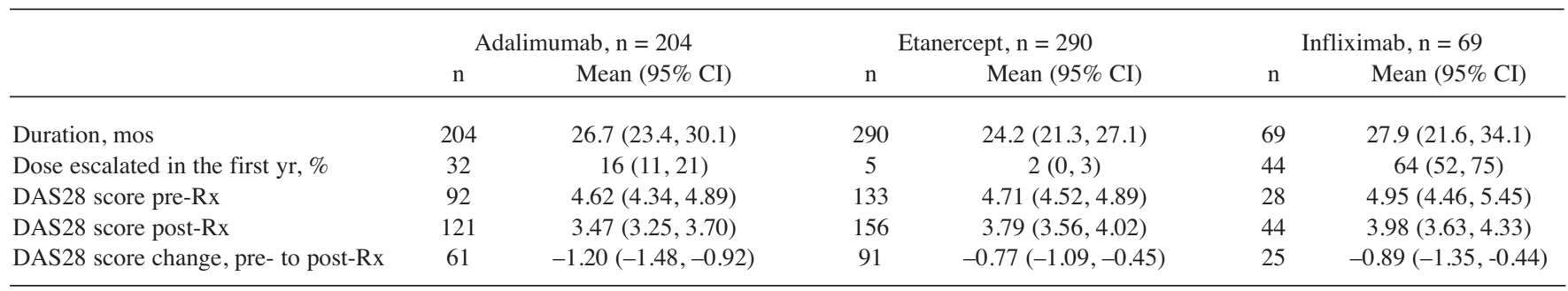

TNFi: tumor necrosis factor inhibitor; RA: rheumatoid arthritis; DAS28: Disease Activity Score based on 28 joints; Rx: treatment.

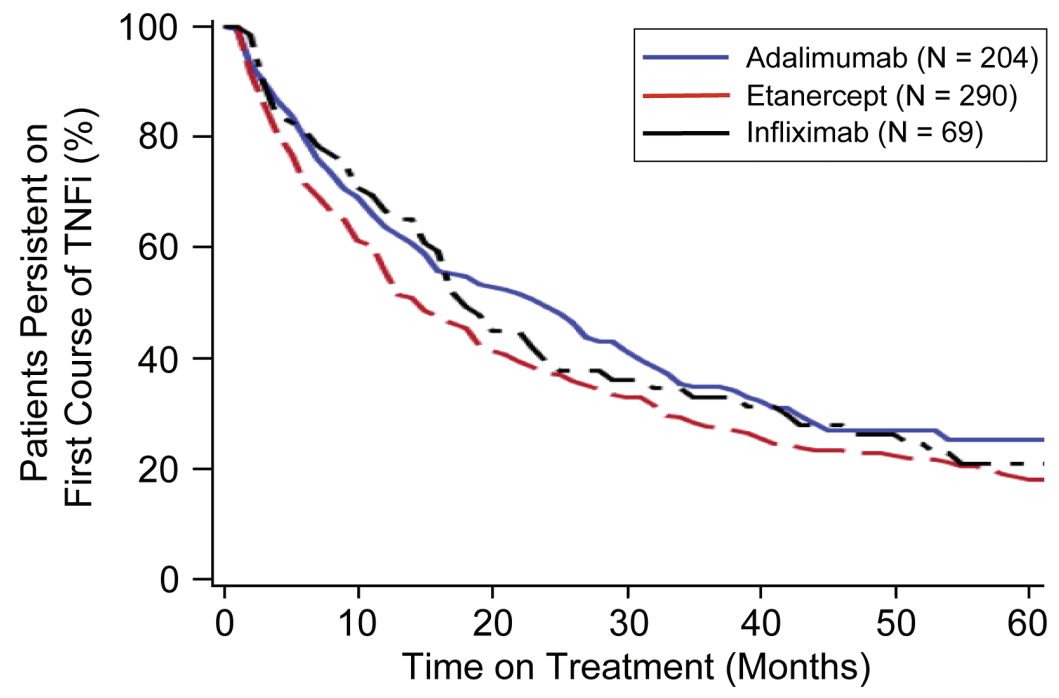

Figure 2. Persistence and dose escalation with TNFi agents. Kaplan-Meier analyses of persistence on first course of treatment for patients with RA receiving adalimumab, etanercept, and infliximab. No statistically significant differences between groups were observed. TNFi: tumor necrosis factor inhibitor; RA: rheumatoid arthritis.

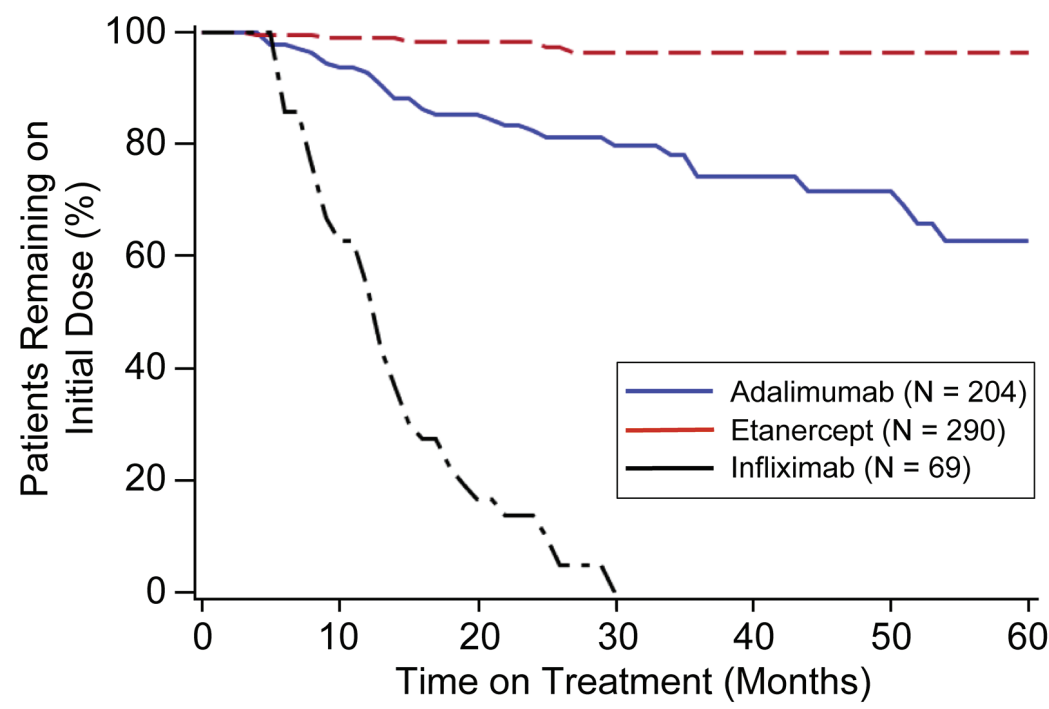

Figure 3. Dose escalation with TNFi agents. Kaplan-Meier analyses of persistence on original dose without escalation in patients receiving adalimumab, etanercept, and infliximab is shown. The differences were statistically significant $(\mathrm{p}<0.01)$. TNFi: tumor necrosis factor inhibitor. 
Table 3. Cost of treatment with multiple courses of TNFi agents in patients with RA.

\begin{tabular}{|c|c|c|c|c|c|c|}
\hline & \multicolumn{2}{|c|}{ Adalimumab, $\mathrm{n}=204$} & \multicolumn{2}{|c|}{ Etanercept, $\mathrm{n}=290$} & \multicolumn{2}{|c|}{ Infliximab, $\mathrm{n}=69$} \\
\hline & $\mathrm{n}$ & Mean $(95 \%$ CI) & $\mathrm{n}$ & Mean $(95 \%$ CI) & $\mathrm{n}$ & Mean $(95 \% \mathrm{CI})$ \\
\hline \multicolumn{7}{|l|}{ First course } \\
\hline Annual cost of drug* & 204 & $\$ 12.9(12.4,13.3)$ & 290 & $\$ 13.2(12.9,13.5)$ & 69 & $\$ 15.3(13.2,17.5)$ \\
\hline Annual drug + administration costs ${ }^{* *}$ & 204 & $\$ 13.1(12.6,13.6)$ & 290 & $\$ 13.5(13.2,13.8)$ & 69 & $\$ 16.9(14.6,19.2)$ \\
\hline \multicolumn{7}{|l|}{ Second course } \\
\hline Duration, mos & 159 & $16.4(13.7,19.1)$ & 105 & $15.8(12.7,18.9)$ & 37 & $21.6(13.8,29.4)$ \\
\hline Annual cost of drug* & 159 & $\$ 13.1(12.5,13.8)$ & 105 & $\$ 11.7(11.1,12.2)$ & 37 & $\$ 18.0(12.4,23.5)$ \\
\hline Annual drug + administration costs ${ }^{* *}$ & 159 & $\$ 13.8(13.1,14.5)$ & 105 & $\$ 12.4(11.9,13.0)$ & 37 & $\$ 19.7(13.8,25.5)$ \\
\hline \multicolumn{7}{|l|}{ Total of all courses } \\
\hline Duration, mos & 204 & $37.6(34.2,41.1)$ & 290 & $39.5(36.3,42.8)$ & 69 & $41.4(34.1,48.7)$ \\
\hline Annual cost of drug & 204 & $\$ 12.6(12.2,13.0)$ & 290 & $\$ 12.9(12.7,13.2)$ & 69 & $\$ 14.0(12.6,15.3)$ \\
\hline Annual drug + administration costs ${ }^{* *}$ & 204 & $\$ 13.0(12.5,13.4)$ & 290 & $\$ 13.3(13.0,13.6)$ & 69 & $\$ 15.2(13.8,16.7)$ \\
\hline Total cost of drug* & 204 & $\$ 39.5(35.2,43.8)$ & 290 & $\$ 41.1(37.5,44.7)$ & 69 & $\$ 44.3(35.7,52.9)$ \\
\hline Total drug + administration costs $* *$ & 204 & $\$ 40.7(36.3,45.1)$ & 290 & $\$ 42.4(38.7,46.1)$ & 69 & $\$ 47.8(38.7,56.9)$ \\
\hline
\end{tabular}

$*$ Cost of drug alone in US $\$ \times 1000$. * Cost of drug plus cost of dispensing drug (adalimumab and etanercept) or infusing drug (infliximab) in US $\$ \times 1000$. TNFi: tumor necrosis factor inhibitor; RA: rheumatoid arthritis.

for ADA and ETN, a difference that was driven by additional costs of administration. Similar patterns in costs were seen during the second drug course, and for all courses of medication according to the initial treatment assignment.

\section{DISCUSSION}

In US veterans with RA enrolled in the VARA registry, rates of persistence were similar among patients receiving ADA, ETN, and IFX during their first course of treatment. Prior studies have reported different persistence rates with TNFi therapy. In the COnsortium of Rheumatology Researchers of North America (CORRONA) database reporting over 24 months of potential TNFi exposure, an analysis of biologic-naive patients showed greater persistence at 12 and 24 months for IFX than for ADA or ETN ${ }^{38}$. Higher persistence with IFX has also been reported in a US pharmacy database analysis ${ }^{39}$, while some European cohorts showed the lowest persistence with $\mathrm{IFX}^{40,41}$. In the Danish registry comparing ADA, ETN, and IFX, persistence was highest with ETN and lowest with IFX, with $56 \%$ and $41 \%$ of patients, respectively, remaining persistent at 2 years ${ }^{42}$. Similar comparative results were reported from an Italian registry in which ETN was stated to have greater persistence than either ADA or IFX, although the overall persistence rates were higher than those seen in our study for all agents ${ }^{43}$. When switching to a second TNFi, no differences in persistence were noted among the agents ${ }^{44}$. These results suggest a variation in persistence in different populations, but overall persistence rates appear similar to those observed in our study.

Dose escalation was significantly more frequent with IFX than with ADA or ETN in our study. It should be noted that dose escalation is described in the ADA and IFX labels, but not in the ETN label, which may have contributed to the low rate of dose escalation with ETN. In a placebo-controlled clinical trial of ADA with or without MTX in which dose escalation from every other week to weekly was mandated in patients not achieving $20 \%$ improvement in the American College of Rheumatology criteria response after 16 weeks, the dose of ADA was escalated in $11 \%$ of patients receiving ADA and MTX, and 25\% of the patients receiving ADA monotherapy ${ }^{6}$. This prior study reported that the increase in ADA administration from every other week to a weekly dose had minimal effects on measures of efficacy ${ }^{6}$. These rates of dose escalation of ADA previously reported ${ }^{6}$ were similar to the rate of $16 \%$ observed in our study. Consistent with our finding, dose escalation was more frequent with IFX than with ADA or ETN in the CORRONA database ${ }^{38}$. Other studies have reported dose escalation to be more common with IFX and ADA than with $\operatorname{ETN}^{19,40,45,46,47}$.

It is important to note that in our study there were no clear differences in clinical outcomes based on DAS28 in patients who underwent dose escalation compared with patients who continued their original dose. Comparative efficacy studies with biologic agents have been limited ${ }^{48,49}$. Registries have generally reported either similar clinical efficacy $^{38}$ or similar rates for discontinuation for effectiveness and adverse events ${ }^{18,42}$, although greater effectiveness has been reported with $\mathrm{ADA}$ in $1 \mathrm{study}^{41}$. No randomized clinical trials have compared the efficacy of different TNFi agents. However, greater clinical improvement in patients with RA beginning their first TNFi agent than in patients switching between TNFi agents has been reported ${ }^{38}$. These data and our observations suggest that dose escalation is often associated with added costs without increased benefit.

The use of biologic agents is associated with significant costs. Several cost benefit analyses have evaluated these treatments and reported that these agents are cost effective by currently acceptable standards, although the cost effec-

Personal non-commercial use only. The Journal of Rheumatology Copyright (C) 2014. All rights reserved 
tiveness may vary according to patient characteristics $22,23,24,25,26$. Similar to our results, other studies have noted higher costs with IFX therapy than with the injectable TNFi agents ${ }^{47,50}$, although 1 study reported higher costs with $\mathrm{ADA}^{40}$. Our data suggest that in a VA population initiating TNFi therapy, the cost of IFX is higher than the cost of ETN and ADA without significant differences in clinical outcomes.

Strengths of our study included the large number of patients with RA, confirmed diagnoses of RA, geographical diversity of the patient population across the United States, and a patient population that largely remained within the VA system. The uniformity of administrative data and the standardized electronic medical record allowed for consistent collection of data across medical centers and standardized calculation of both treatment courses and costs. The ability to correlate information from the administrative databases with clinical outcomes allows the assessment of drug persistence, dose escalations, cost, and clinical responses across a national dataset. The VA has allowed the use of TNFi agents in patients requiring biologic therapy without restriction to specific agents, thus allowing a comparison of use of all agents available for VA prescription. This benefit makes it less likely that VA patients will discontinue biologic agents because of cost.

Our patient population was US veterans who are predominantly men with longstanding RA; they may not represent the most commonly affected population in RA, thereby limiting the generalizability of our findings. The sole source of information on biologic agents was from the VA databases and we were unable to ensure that patients were not receiving biologic agents from other sources outside the VA; however, our experience is that US veterans receiving their care through the VA are very unlikely to receive biologic agents from outside sources owing to the high cost of treatment and the availability of the benefit in the VA. The VA has the benefit of federal contracts for TNFi therapy, which can provide its patients these agents at a cost that may not be available to the general public. Also, administrative costs as reported are the incremental costs for the dispensing and infusion. These differences in pricing may make it difficult to compare our results to non-federal funding systems. Our study could not determine the factors associated with the selection of a specific biologic agent or the discontinuation of an agent. Such factors could confound the observed results.

In the VARA registry, persistence was similar for all 3 TNFi agents, but dose escalation was more frequent with IFX and ADA than with ETN. Clinical responses to these therapies were similar during the first course of TNFi therapy, as well as after switching to a second agent. Initial treatment with IFX was associated with higher cost without significant difference in clinical outcomes in comparison with ADA and ETN. The cost difference was associated with a high rate of dose escalation in patients receiving IFX in comparison with ADA and ETN. Because of intrinsic potential confounding factors in observational studies, additional studies are required to provide information on treatment patterns and clinical outcomes to assist the clinician in selecting TNFi agents for the treatment of patients with RA.

\section{ACKNOWLEDGMENT}

We thank Edward Mancini (Amgen Inc.) and Julia R. Gage (on behalf of Amgen Inc.) for medical writing support.

\section{REFERENCES}

1. Gullick NJ, Scott DL. Co-morbidities in established rheumatoid arthritis. Best Pract Res Clin Rheumatol 2011;25:469-83.

2. Carmona L, Cross M, Williams B, Lassere M, March L. Rheumatoid arthritis. Best Pract Res Clin Rheumatol 2010; 24:733-45.

3. McInnes IB, O'Dell JR. State-of-the-art: rheumatoid arthritis. Ann Rheum Dis 2010;69:1898-906.

4. Sokka T, Abelson B, Pincus T. Mortality in rheumatoid arthritis: 2008 update. Clin Exp Rheumatol 2008;26:S35-61.

5. Mikuls TR, Fay BT, Michaud K, Sayles H, Thiele GM, Caplan L, et al. Associations of disease activity and treatments with mortality in men with rheumatoid arthritis: results from the VARA registry. Rheumatology 2011;50:101-9.

6. Breedveld FC, Weisman MH, Kavanaugh AF, Cohen SB, Pavelka $\mathrm{K}$, van Vollenhoven R, et al. The PREMIER study: A multicenter, randomized, double-blind clinical trial of combination therapy with adalimumab plus methotrexate versus methotrexate alone or adalimumab alone in patients with early, aggressive rheumatoid arthritis who had not had previous methotrexate treatment. Arthritis Rheum 2006;54:26-37.

7. Lipsky PE, van der Heijde DM, St Clair EW, Furst DE, Breedveld FC, Kalden JR, et al. Infliximab and methotrexate in the treatment of rheumatoid arthritis. Anti-Tumor Necrosis Factor Trial in Rheumatoid Arthritis with Concomitant Therapy Study Group. N Engl J Med 2000;343:1594-602.

8. van der Heijde D, Klareskog L, Landewe R, Bruyn GA, Cantagrel A, Durez P, et al. Disease remission and sustained halting of radiographic progression with combination etanercept and methotrexate in patients with rheumatoid arthritis. Arthritis Rheum 2007;56:3928-39.

9. Klareskog L, van der Heijde D, de Jager JP, Gough A, Kalden J, Malaise M, et al. Therapeutic effect of the combination of etanercept and methotrexate compared with each treatment alone in patients with rheumatoid arthritis: double-blind randomised controlled trial. Lancet 2004;363:675-81.

10. O'Dell JR, Mikuls TR, Taylor TH, Ahluwalia V, Brophy M, Warren SR, et al. Therapies for active rheumatoid arthritis after methotrexate failure. N Engl J Med 2013;369:307-18.

11. Moreland LW, O'Dell JR, Paulus HE, Curtis JR, Bathon JM, St Clair EW, et al. A randomized comparative effectiveness study of oral triple therapy versus etanercept plus methotrexate in early aggressive rheumatoid arthritis: the treatment of Early Aggressive Rheumatoid Arthritis Trial. Arthritis Rheum 2012;64:2824-35.

12. van Vollenhoven RF, Ernestam S, Geborek P, Petersson IF, Coster $\mathrm{L}$, Waltbrand E, et al. Addition of infliximab compared with addition of sulfasalazine and hydroxychloroquine to methotrexate in patients with early rheumatoid arthritis (Swefot trial): 1-year results of a randomised trial. Lancet 2009;374:459-66.

13. Cohen S, Hurd E, Cush J, Schiff M, Weinblatt ME, Moreland LW, et al. Treatment of rheumatoid arthritis with anakinra, a

Personal non-commercial use only. The Journal of Rheumatology Copyright (C) 2014. All rights reserved 
recombinant human interleukin-1 receptor antagonist, in combination with methotrexate: results of a twenty-four-week, multicenter, randomized, double-blind, placebo-controlled trial. Arthritis Rheum 2002;46:614-24.

14. Kremer JM, Genant HK, Moreland LW, Russell AS, Emery P, Abud-Mendoza C, et al. Effects of abatacept in patients with methotrexate-resistant active rheumatoid arthritis: a randomized trial. Ann Intern Med 2006;144:865-76.

15. Emery P, Fleischmann R, Filipowicz-Sosnowska A, Schechtman J, Szczepanski L, Kavanaugh A, et al. The efficacy and safety of rituximab in patients with active rheumatoid arthritis despite methotrexate treatment: results of a phase IIB randomized, double-blind, placebo-controlled, dose-ranging trial. Arthritis Rheum 2006;54:1390-400.

16. Agarwal SK. Biologic agents in rheumatoid arthritis: an update for managed care professionals. J Manag Care Pharm 2011;17:S14-8.

17. Moots RJ, Naisbett-Groet B. The efficacy of biologic agents in patients with rheumatoid arthritis and an inadequate response to tumour necrosis factor inhibitors: a systematic review. Rheumatology 2012;51:2252-61.

18. Hyrich KL, Lunt M, Watson KD, Symmons DP, Silman AJ. Outcomes after switching from one anti-tumor necrosis factor alpha agent to a second anti-tumor necrosis factor alpha agent in patients with rheumatoid arthritis: results from a large UK national cohort study. Arthritis Rheum 2007;56:13-20.

19. Fisher MD, Watson C, Fox KM, Chen YW, Gandra SR. Dosing patterns of three tumor necrosis factor blockers among patients with rheumatoid arthritis in a large United States managed care population. Curr Med Res Opin 2013;29:561-8.

20. Curtis JR, Chen L, Luijtens K, Navarro-Millan I, Goel N, Gervitz $\mathrm{L}$, et al. Dose escalation of certolizumab pegol from $200 \mathrm{mg}$ to 400 mg every other week provides no additional efficacy in rheumatoid arthritis: an analysis of individual patient-level data. Arthritis Rheum 2011;63:2203-8.

21. Weinblatt ME, Schiff MH, Ruderman EM, Bingham CO 3rd, Li J, Louie J, et al. Efficacy and safety of etanercept $50 \mathrm{mg}$ twice a week in patients with rheumatoid arthritis who had a suboptimal response to etanercept $50 \mathrm{mg}$ once a week: results of a multicenter, randomized, double-blind, active drug-controlled study. Arthritis Rheum 2008;58:1921-30.

22. Finckh A. Comparative effectiveness of rheumatoid arthritis therapies. Curr Rheumatol Rep 2010;12:348-54.

23. Malottki K, Barton P, Tsourapas A, Uthman AO, Liu Z, Routh K, et al. Adalimumab, etanercept, infliximab, rituximab and abatacept for the treatment of rheumatoid arthritis after the failure of a tumour necrosis factor inhibitor: a systematic review and economic evaluation. Health Technol Assess 2011;15:1-278.

24. Puolakka K, Blafield H, Kauppi M, Luosujarvi R, Peltomaa R, Leikola-Pelho T, et al. Cost-effectiveness modelling of sequential biologic strategies for the treatment of moderate to severe rheumatoid arthritis in Finland. Open Rheumatol J 2012;6:38-43.

25. Chen YF, Jobanputra P, Barton P, Jowett S, Bryan S, Clark W, et al. A systematic review of the effectiveness of adalimumab, etanercept and infliximab for the treatment of rheumatoid arthritis in adults and an economic evaluation of their cost-effectiveness. Health Technol Assess 2006;10:1-229.

26. Finckh A, Bansback N, Marra CA, Anis AH, Michaud K, Lubin S, et al. Treatment of very early rheumatoid arthritis with symptomatic therapy, disease-modifying antirheumatic drugs, or biologic agents: a cost-effectiveness analysis. Ann Intern Med 2009;151:612-21.

27. Curtis JR, Baddley JW, Yang S, Patkar N, Chen L, Delzell E, et al. Derivation and preliminary validation of an administrative claims-based algorithm for the effectiveness of medications for rheumatoid arthritis. Arthritis Res Ther 2011;13:R155.

28. Cannon GW, Mikuls TR, Hayden CL, Ying J, Curtis JR, Reimold
AM, et al. Merging Veterans Affairs rheumatoid arthritis registry and pharmacy data to assess methotrexate adherence and disease activity in clinical practice. Arthritis Care Res 2011;63:1680-90.

29. Mikuls TR, Kazi S, Cipher D, Hooker R, Kerr GS, Richards JS, et al. The association of race and ethnicity with disease expression in male US veterans with rheumatoid arthritis. J Rheumatol 2007;34:1480-4.

30. Arnett FC, Edworthy SM, Bloch DA, McShane DJ, Fries JF, Cooper NS, et al. The American Rheumatism Association 1987 revised criteria for the classification of rheumatoid arthritis. Arthritis Rheum 1988;31:315-24.

31. Smith MW, Joseph GJ. Pharmacy data in the VA health care system. Med Care Res Rev 2003;60:92S-123S.

32. Washington: United States Department of Veterans Affairs. VA Informatics and Computing Infrastructure Corporate Data Warehouse (CDW), updated 2009. [Internet. Accessed July 24, 2014.] Available from: www.hsrd.research.va.gov/for_researchers/vinci/cdw.cfm

33. Washington: United States Department of Veterans Affairs Decision Support System (DSS), 2013. [Internet. Accessed July 24, 2014.] Available from: www.herc.research.va.gov/data/dss.asp

34. Washington: United States Department of Veterans Affairs. Pharmacy Benefits Management Services, 2013. [Internet. Accessed July 24, 2014.] Available from: www.pbm.va.gov/

35. Prevoo ML, van't Hof MA, Kuper HH, van Leeuwen MA, van de Putte LB, van Riel PL. Modified disease activity scores that include twenty-eight-joint counts. Development and validation in a prospective longitudinal study of patients with rheumatoid arthritis. Arthritis Rheum 1995;38:44-8.

36. Poole C. Beyond the confidence interval. Am J Public Health 1987;77:195-9.

37. Poole C. Low P-values or narrow confidence intervals: which are more durable? Epidemiology 2001;12:291-4.

38. Greenberg JD, Reed G, Decktor D, Harrold L, Furst D, Gibofsky A, et al. A comparative effectiveness study of adalimumab, etanercept and infliximab in biologically naive and switched rheumatoid arthritis patients: results from the US CORRONA registry. Ann Rheum Dis 2012;71:1134-42.

39. Tang B, Rahman M, Waters HC, Callegari P. Treatment persistence with adalimumab, etanercept, or infliximab in combination with methotrexate and the effects on health care costs in patients with rheumatoid arthritis. Clin Ther 2008;30:1375-84.

40. Ramirez-Herraiz E, Escudero-Vilaplana V, Alanon-Plaza E, Trovato-Lopez N, Herranz-Alonso A, Morell-Baladron A, et al. Efficiency of adalimumab, etanercept and infliximab in rheumatoid arthritis patients: dosing patterns and effectiveness in daily clinical practice. Clin Exp Rheumatol 2013;31:559-65.

41. Kievit W, Adang EM, Fransen J, Kuper HH, van de Laar MA, Jansen TL, et al. The effectiveness and medication costs of three anti-tumour necrosis factor alpha agents in the treatment of rheumatoid arthritis from prospective clinical practice data. Ann Rheum Dis 2008;67:1229-34.

42. Hetland ML, Christensen IJ, Tarp U, Dreyer L, Hansen A, Hansen IT, et al. Direct comparison of treatment responses, remission rates, and drug adherence in patients with rheumatoid arthritis treated with adalimumab, etanercept, or infliximab: results from eight years of surveillance of clinical practice in the nationwide Danish DANBIO registry. Arthritis Rheum 2010;62:22-32.

43. Iannone F, Gremese E, Atzeni F, Biasi D, Botsios C, Cipriani P, et al. Longterm retention of tumor necrosis factor-alpha inhibitor therapy in a large Italian cohort of patients with rheumatoid arthritis from the GISEA registry: an appraisal of predictors. J Rheumatol 2012;39:1179-84.

44. Markenson JA, Gibofsky A, Palmer WR, Keystone EC, Schiff MH, Feng J, et al. Persistence with anti-tumor necrosis factor therapies 
in patients with rheumatoid arthritis: observations from the RADIUS registry. J Rheumatol 2011;38:1273-81.

45. Bonafede MM, Gandra SR, Fox KM, Wilson KL. Tumor necrosis factor blocker dose escalation among biologic naive rheumatoid arthritis patients in commercial managed-care plans in the 2 years following therapy initiation. J Med Econ 2012;15:635-43.

46. Blume SW, Fox KM, Joseph G, Chuang CC, Thomas J, Gandra SR. Tumor necrosis factor-blocker dose escalation in rheumatoid arthritis patients in a pharmacy benefit management setting. Adv Ther 2013;30:517-27.

47. Ollendorf DA, Klingman D, Hazard E, Ray S. Differences in annual medication costs and rates of dosage increase between tumor necrosis factor-antagonist therapies for rheumatoid arthritis in a managed care population. Clin Ther 2009;31:825-35.
48. Weinblatt ME, Schiff M, Valente R, van der Heijde D, Citera G, Zhao C, et al. Head-to-head comparison of subcutaneous abatacept versus adalimumab for rheumatoid arthritis: findings of a phase IIIb, multinational, prospective, randomized study. Arthritis Rheum 2013;65:28-38.

49. Schiff M, Keiserman M, Codding C, Songcharoen S, Berman A, Nayiager S, et al. Efficacy and safety of abatacept or infliximab vs placebo in ATTEST: a phase III, multi-centre, randomised, double-blind, placebo-controlled study in patients with rheumatoid arthritis and an inadequate response to methotrexate. Ann Rheum Dis 2008;67:1096-103.

50. Weycker D, Yu EB, Woolley JM, Oster G. Retrospective study of the costs of care during the first year of therapy with etanercept or infliximab among patients aged $>$ or $=65$ years with rheumatoid arthritis. Clin Ther 2005;27:646-56. 